Proc. Estonian Acad. Sci. Eng., 2004, 10, 4, 251-260

\title{
A 3D turning system to reduce geometry errors of flexible rotors
}

\author{
Thomas Widmaier $^{\mathrm{a}}$, Petri Kuosmanen ${ }^{\mathrm{a}}$, Janne Haikio ${ }^{\mathrm{b}}$ \\ and Pekka Väänänen ${ }^{\mathrm{b}}$ \\ a Laboratory of Machine Design, Helsinki University of Technology, P.O. Box 4400 FIN-02015 \\ HUT, Helsinki, Finland; \{Thomas.Widmaier, Petri.Kuosmanen\} @ hut.fi \\ b RollResearch International Ltd., P.O. Box 10 FIN-02151, Espoo, Finland; \{Janne.Haikio, \\ Pekka.Vaananen\}@ rollresearch.fi
}

Received 1 July 2004, in revised form 25 August 2004

\begin{abstract}
Increased running speed and reduction of accepted vibration levels in paper machines have set new demands for the roundness and cylindricity of paper machine rolls. The diameter variation is mainly caused by the slideway straightness error of the machine tool. The rotational errors during the machining process come about because of the changing distance between the roll axis and the tool and are copied to the roundness error in the roll. A 3D turning system, including a measuring device, was developed to compensate systematic roll geometry errors. The non-circular turning method was applied to a supercalender roll. The 3D turning reduced the average roundness error in the test roll by $62 \%$, the diameter variation in the axial direction was reduced by $83 \%$ and the $3 \mathrm{D}$ geometry error by $78 \%$.
\end{abstract}

Key words: roll, roundness, measuring, non-circular turning.

\section{INTRODUCTION}

\subsection{Background}

The flexible rotors, studied in this paper, are supercalender paper machine rolls. The methods described here can also be applied for other kinds of flexible rotors.

The dominant trend in paper machines is towards increased running speed. The running speeds of new paper machines may reach $35 \mathrm{~m} / \mathrm{s}$. At the same time, the accepted vibration levels in paper machines have been reduced. These two coexisting factors create new demands on the roundness and cylindricity of large rolls (with a diameter of 500-2000 mm, length of 5-12 $\mathrm{m}$ and mass of 5-100 t). 


\subsection{Research problem}

To date, the roundness and diameter variation tolerance of soft-covered nip rolls has been $50 \mu \mathrm{m}$, but should be substantially reduced in the future. The workpiece diameter variation is mainly caused by the slideway straightness error of the machine tool. There are also other systematic error sources as, for example, tool wear and thermal deflection. Increasing the accuracy of traditional machining technology is no longer possible because of the cost involved.

Although there are commercial turning systems that reduce the crossdirectional $(\mathrm{CD})$ diameter variation in the rolls, it is also important to reduce roll geometry errors that cause machine-directional (MD) variations. These roll geometry errors can be divided into roundness errors and run-out errors. These errors correlate with the runnability and vibration level of the paper machine. They also correlate with MD paper quality variations $\left[^{1}\right]$. Roundness errors are more important than run-out errors in calender rolls as they are in a stack.

The roundness error can also be a source for diameter variation (Fig. 1, a) $\left[{ }^{2}\right]$. More specifically, only the even lobes of the waveform in the roundness profile have an effect on the diameter variation. However, if the amplitude and phase of even lobes of the roundness profile are the same at all cross-sections of the roll, the roundness error has no effect on the axial diameter variation (Fig. 1, b). The relation between odd lobes of the roundness profile and the diameter is discussed in $\left[^{3}\right]$.

The roundness errors of a roll during the machining process is caused by the changing distance between the workpiece axis of rotation and the tool. In machining paper machine rolls, the tool is normally quite steady, but the workpiece has a rotational error, which will be copied to the roundness error. In addition to vibrations, the main sources of the rotational errors are the changing beam moment of inertia of flexible rolls and inaccuracies in the bearing system during the machining process.

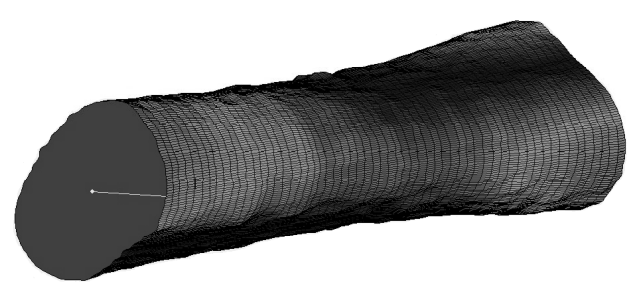

(a)

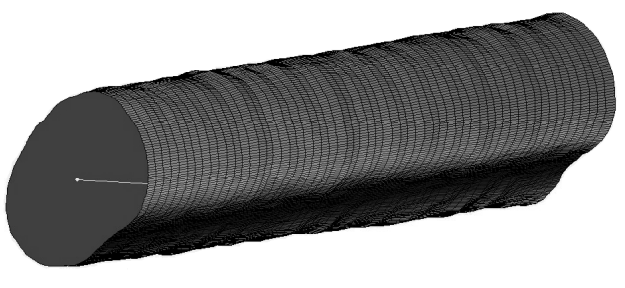

(b)

Fig. 1. (a) Diameter variation in axial direction caused mainly by roundness error; (b) almost no axial diameter variation. 


\subsection{Aim of the research}

The aim of this study is to develop a turning system to reduce systematic roll roundness errors and roll diameter variations (3D turning). From the roll measurements, a calculated 3D correction profile is created for the turning system. The main elements of the system are a pre-existing four-point measuring system, which can verify the rotational and geometry errors of the roll, and a turning system, which controls the turning process in accordance with the measured information.

\subsection{Research methods}

This paper focuses on experimental research and on the analysis of measured quantities. The experiments are carried out in a paper mill environment with rolls used in the paper production line. The roll geometry is measured after conventional turning and after 3D turning.

The roll measurement system utilizes the Fourier transform. The calculation of the 3D correction profile utilizes the Newton form of the interpolation polynomial.

\subsection{Scope of the research}

The reduction of roll geometry errors, originating from non-systematic error sources (for example, resonance vibrations), are excluded from this study. In addition, dynamic changes in the roll geometry under production conditions in the paper machine are not examined. High rotational speeds can cause significant changes in the roll geometry $\left[^{2,4,5}\right]$.

\section{METHODS}

\subsection{Equipment}

The equipment consists of a four-point measuring system and a 3D turning system (Fig. 2). It can be installed, for example, on a lathe for paper machine rolls. Both systems were developed in the Laboratory of Machine Design at the Helsinki University of Technology (HUT) and they are commercially available. The lathe used for the turning tests is a roll lathe with a slideway of about $10 \mathrm{~m}$ total length.

\subsubsection{Measuring system}

The roll-measuring device used in this study is a four-point measuring device developed in the laboratory of Machine Design at HUT [ $\left.{ }^{6}\right]$ (Fig. 3). The fourpoint measuring method uses four sensors in a combination of a three-point 


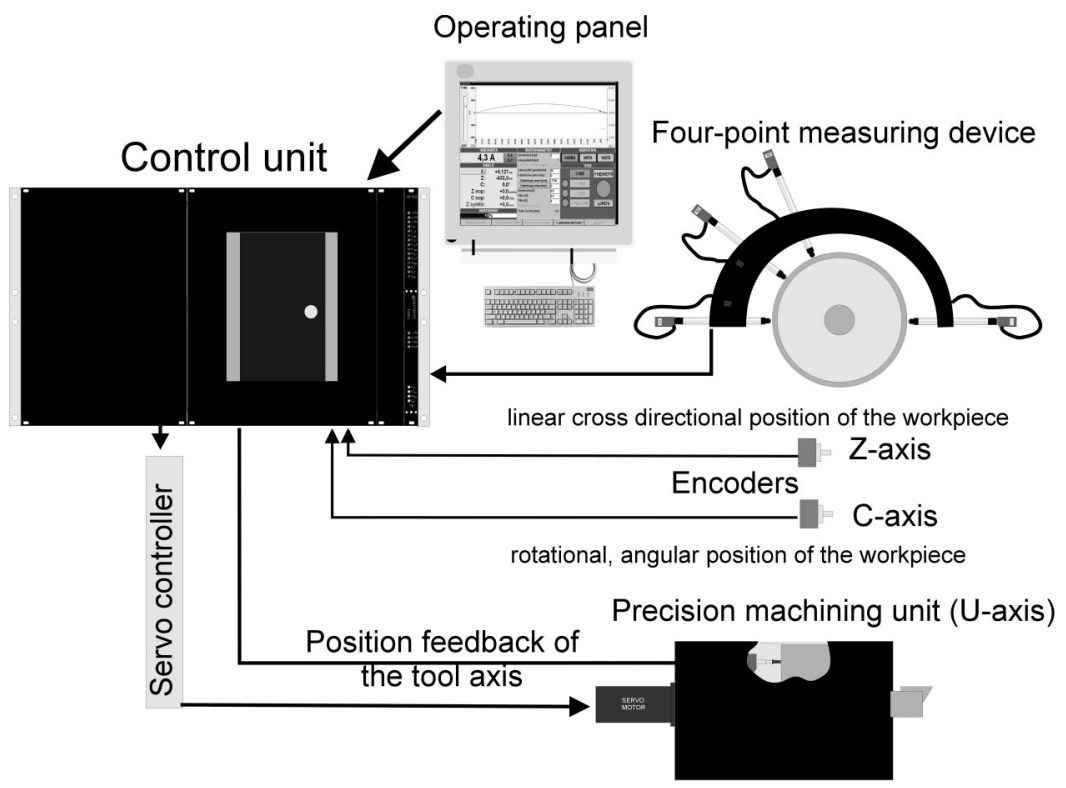

Fig. 2. Generic description of the 3D measuring and turn control system.

method and a two-point method. The two-point method has been used, for example, in caliper rules or measuring devices for conventional roll grinders or lathes. The three-point method can be used for roundness measurements $\left[^{7}\right]$. The four-point method combines them in a new, more accurate method $\left[{ }^{8}\right]$.

The measuring device is capable of measuring the diameter variation (CD-profile) and the roundness profile (MD-profile) of a large-scale cylindrical object, for example, of a paper machine roll. The measuring accuracy is $\pm 1 \mu \mathrm{m}$ $\left[{ }^{9}\right]$. According to the manufacturer, the optical length gauges in the device have a measuring accuracy of $\pm 0.2 \mu \mathrm{m}$.

For the rotational position of the roll (C-axis) a rotary encoder with 1024 pulses per revolution was used. In addition, the linear cross (Z-axis) movement was equipped with a similar rotary encoder.

The C-frame of the device was made of carbon fibre. This ensures stability against thermal expansion and overall stiffness combined with a low frame weight. For the data acquisition, the control unit reads and stores the raw measurement data in a database. From there, the measurements can be retrieved, filtered and displayed on a computer display or printed out.

\subsubsection{The $3 D$ turning system}

The 3D turning system consists of the control unit, the precision-machining unit and an analogue servo controller. The precision-machining unit is equipped with a servomotor. A general view of the precision-machining unit is shown in Fig. 3. 


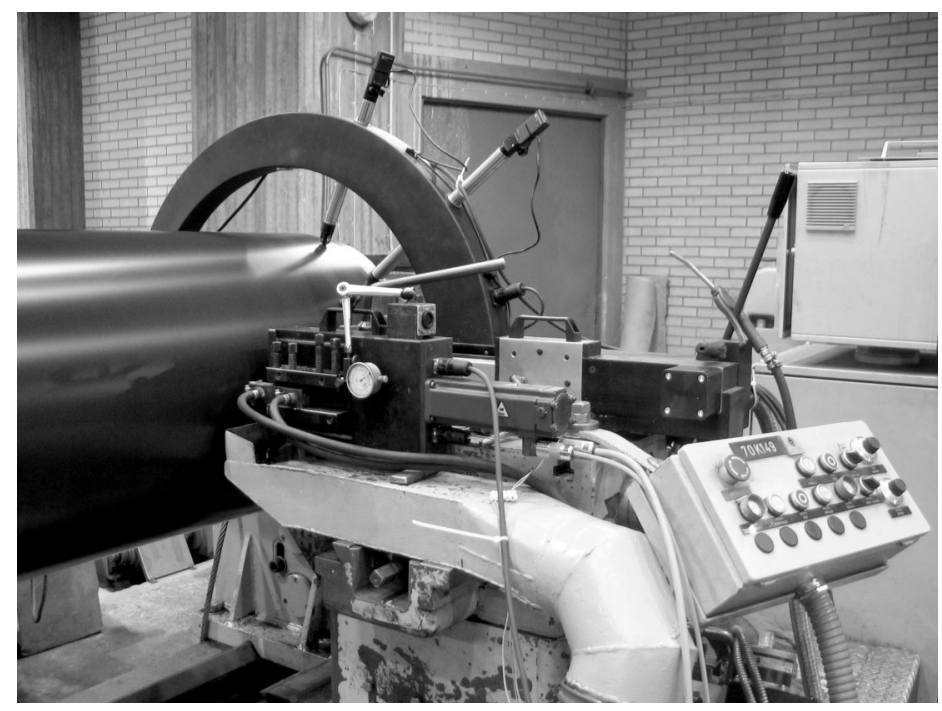

Fig. 3. The measuring device and the precision-machining unit installed on a lathe.

Control unit. The control unit includes two PC CPU boards, a motion control board, two measuring cards, a dual ported memory card and a DC/DC power supply. One of the PCs is used as a user interface. The interface computer has Windows NT as its operating system. In the interface computer there is also a database for the measurements, roll data, machining data, etc. This computer is also used for filtering and for calculating the correction profile for the $3 \mathrm{D}$ turning. The turning process can also be monitored via the interface.

The second PC, the NC unit, is used to control the tool axis and measurements. The correct path for the tool axis is calculated from the positions of the $\mathrm{C}$ - and Z-axes. The motion control board controls the tool axis with an analogue velocity signal. The feedback signal for the closed-loop control system comes from an optical linear gauge that is installed in the precision-machining unit. Two 2-channel measurement cards read the signals from the four measurement sensors. The software reads the signals at a pace that is determined by the changes in the position of the Z-axis and the angle of the $\mathrm{C}$-axis. The communication between the two computers takes place over the dual ported memory card.

All the computer boards and measurement cards are packed into a small aluminium box. This box is called the computer unit and it can be taken out and replaced with a new one without disconnecting the cabling. The computer unit and the internal cabling of the system are placed inside a 19" rack, which can be installed for example in an electric cabinet.

Precision-machining unit. In the precision-machining unit, the cutting tool is fastened to a tool-holder (Fig. 4). The toolholder is fastened to a slide that can be moved by a servomotor. The position of the slide is measured with an optical 


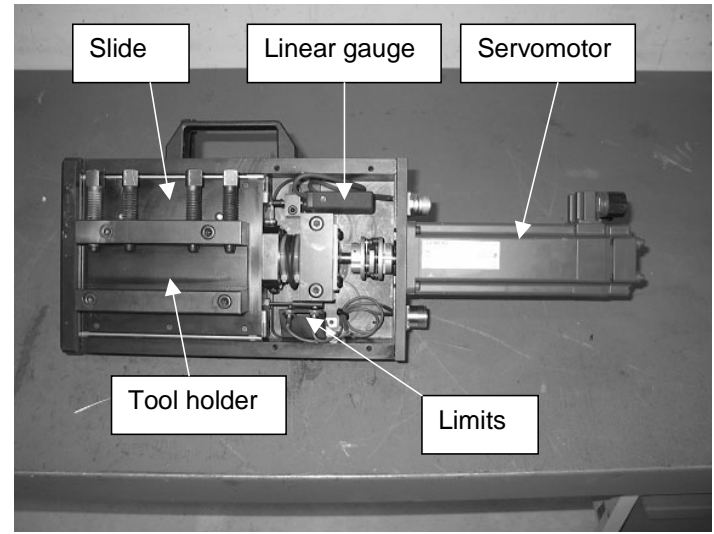

Fig. 4. Precision-machining unit with position feedback sensor, inductive limit sensors and a servomotor.

linear gauge. The servomotor is a normal analogue AC-servomotor that is used together with a servo control unit. In the precision-machining unit, there are two inductive sensors. One of the sensors is used for referencing the homing position and also as a work area limit sensor. The other one is used only as a work area limit sensor. All this is placed inside a rigid steel housing with connectors for the limits and position encoder. The step response and other properties of a precision-machining unit with another AC-servomotor have been measured previously by Haikio $\left[{ }^{10}\right]$.

\subsection{Calculation of the $3 \mathrm{D}$ correction profile}

The correction profile for the 3D turning is created from measurements, gained after conventional turning. For the correction profile, one diameter variation measurement and three roundness measurements are needed. The three roundness profiles are measured from both ends of the roll and one in the middle. From the three roundness profiles a calculated 3D roundness profile is created with the help of the Newton form of the interpolation polynomial $\left[{ }^{11}\right]$.

$$
p_{k}(x)=\sum_{i=0}^{k} c_{i} \prod_{j=0}^{i-1}\left(x-x_{j}\right) .
$$

In this study $x$ is replaced with $z, p(x)$ with $m d\left(z, c_{n}\right)$ and $c_{i}$ with $k_{i}$. A polynomial of the second degree is used because there are three zeros present and they "behave" well unlike polynomials of higher degrees.

In Table $1, m d_{1}, m d_{2}$ and $m d_{3}$ are three measured roundness profiles, $c_{n}$ represents the roll angle divided into 256 steps $(0,1,2, \ldots, 255)$ and $z$ is the roll position in the $\mathrm{Z}$-axis direction; $z_{0}, z_{1}$ and $z_{2}$ are the $\mathrm{Z}$-axis positions, where the roundness profiles were measured:

$$
m d_{3 d}\left(z, c_{n}\right)=k_{0}\left(c_{n}\right)+k_{1}\left(c_{n}\right)\left(z-z_{0}\right)+k_{2}\left(c_{n}\right)\left(z-z_{0}\right)\left(z-z_{1}\right) .
$$


Table 1. Three zeros for the Newton form of the interpolation polynomial

\begin{tabular}{c|c|c|c}
\hline$z$ & $z_{0}$ & $z_{1}$ & $z_{2}$ \\
\hline$m d\left(z, c_{n}\right)$ & $m d_{1}\left(c_{n}\right)$ & $m d_{2}\left(c_{n}\right)$ & $m d_{3}\left(c_{n}\right)$
\end{tabular}

The coefficients $k_{0}\left(c_{n}\right), k_{1}\left(c_{n}\right)$ and $k_{2}\left(c_{n}\right)$ in Eq. (2) can be calculated inside the subroutine to create the calculated $3 \mathrm{D}$ roundness profile (Fig. 5). With the calculated 3D roundness profile, the diameter variation that is caused by the roundness error can be subtracted from the diameter variation profile:

$$
c d_{\text {rest }}(z)=c d_{c}(z)-\left(m d_{3 d}\left(z, c_{n}(c)\right)+m d_{3 d}\left(z, c_{n}\left(c+180^{\circ}\right)\right)\right)
$$

where

$$
c_{n}(c)=\frac{c}{360^{\circ}} \times 256, \quad 0^{\circ} \leq c<360^{\circ},
$$

$c$ is the $\mathrm{C}$-axis angle and $c d_{c}(z)$ is the measured diameter variation along the $\mathrm{Z}$-axis at $\mathrm{C}$-axis angle $c$.

Equations (2) and (3), added together and multiplied by -1 give an approximation of the needed correction profile

$$
\operatorname{corr}_{3 d}\left(z, c_{n}\right)=-\left(m d_{3 d}\left(z, c_{n}\right)+c d_{r e s t}(z)\right) .
$$

This calculated 3D correction profile (Fig. 6) can be filtered before it is sent to the PC controlling the tool axis and used as a tool path while turning the roll.

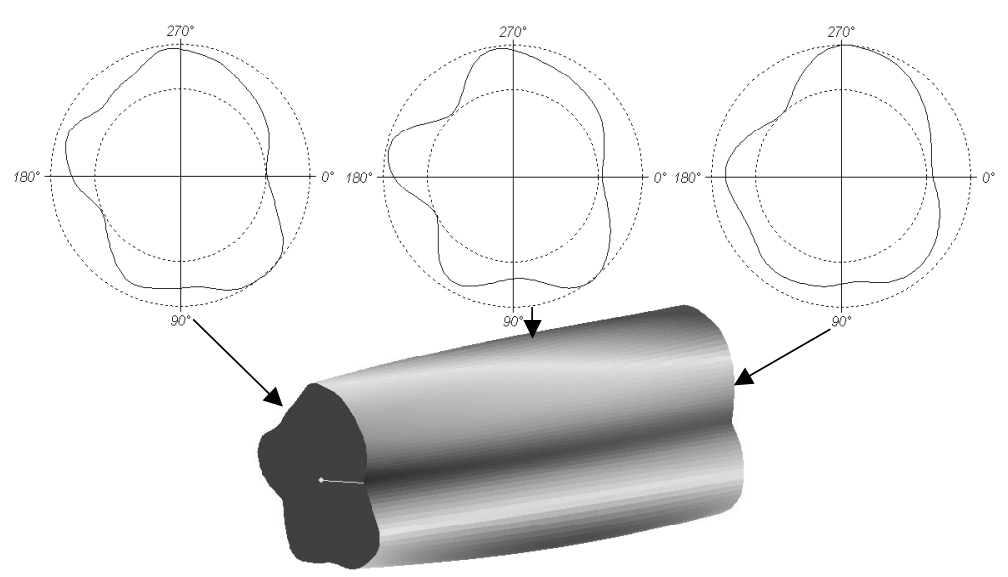

Fig. 5. Creation of the calculated $3 \mathrm{D}$ roundness profile from three roundness profiles. 


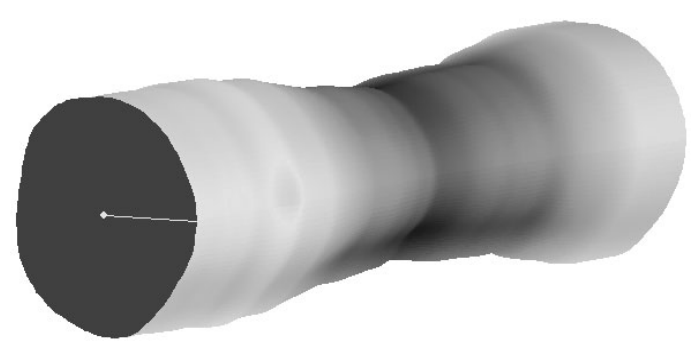

Fig. 6. Calculated 3D correction profile.

\subsection{Experiment}

A test roll was machined using 3D turning technology. This roll is a supercalender fibre roll in a paper mill. Its diameter was $607 \mathrm{~mm}$ and length $5600 \mathrm{~mm}$.

First, the roll was turned conventionally and then a CD-measurement, three MD-measurements and a 3D-measurement were performed. A 3D correction profile was generated from the MD- and CD-profiles (see Chap. 2.2). The correction profile was sent to the NC-unit in the control unit and used as a path for the tool axis for the second turning. After the 3D turning, the roll was measured again.

The rotational speed of the roll while turning was $156 \mathrm{rpm}$ and the cutting speed was $0.56 \mathrm{~mm} / \mathrm{r}$. The toolholder was water-cooled to minimize thermal expansion and a round diamond-coated turning tool was used.

\section{RESULTS}

All the results are filtered with an FFT-filter up to 15 waveforms in roundness profiles and up to 30 in diameter variation. Figure 7 gives an overall impression of the results. Table 2 contains all the measured results for the turned roll.

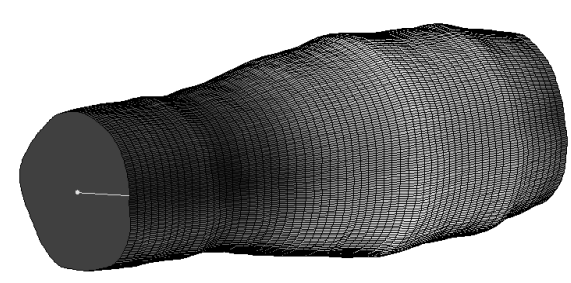

(a)

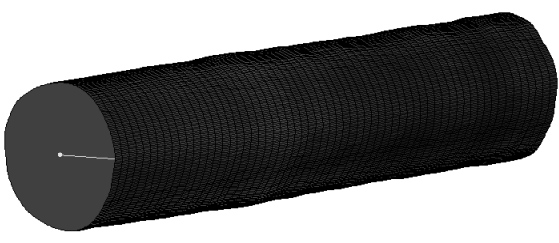

(b)

Fig. 7. Roll geometry after conventional (a) and 3D (b) turning. 
Table 2. Results of the measurements of the test roll after conventional and 3D turning

\begin{tabular}{l|c|c|c|c|c}
\hline & \multirow{2}{*}{$\begin{array}{c}\text { 3D geometry } \\
\text { error }\end{array}$} & $\begin{array}{c}\text { CD maximum } \\
\text { diameter }\end{array}$ & \multicolumn{3}{|c}{ Roundness error } \\
\cline { 5 - 6 } & & variation & Left end & Middle & Right end \\
\hline Conventional turning & $107 \mu \mathrm{m}$ & $154.5 \mu \mathrm{m}$ & $27.0 \mu \mathrm{m}$ & $36.0 \mu \mathrm{m}$ & $38.0 \mu \mathrm{m}$ \\
3D turning & $23 \mu \mathrm{m}$ & $25.8 \mu \mathrm{m}$ & $12.0 \mu \mathrm{m}$ & $16.0 \mu \mathrm{m}$ & $13.0 \mu \mathrm{m}$ \\
Error reduction & $78.5 \%$ & $83.3 \%$ & $55.6 \%$ & $55.6 \%$ & $65.8 \%$
\end{tabular}

\section{DISCUSSION}

As can be seen from Table 2, this method can significantly reduce systematic errors arising from slideway errors from the lathe and roundness errors, resulting from the rotational error of the workpiece during the machining process. The diameter variation in the test roll is mainly caused by the slideway straightness error of the lathe. This assumption can be made, because all the rolls turned with the same lathe have a similar diameter variation profile. If the slideway straightness error were measured, it could then be used as the basic correction curve in the lathe for all the rolls to be machined. This would reduce the need for the second turning, if the original roundness error of the roll is small enough.

The effects of this turning method in the supercalender have not been analysed yet. The effect of the diameter variation profile has been studied previously by Kuosmanen $\left[{ }^{4}\right]$. In that study, it is shown that an improved roll diameter variation profile reduces $\mathrm{CD}$ thickness and gloss variations in the paper. From these results, one could assume that if this method can also reduce machine-directional variations in the roll profiles, this will have a positive effect on the paper quality in the MD direction compared with the sole $\mathrm{CD}$ profile correction. Because, as was stated in the introduction, the reduction in the roundness errors can also reduce the diameter variations on certain rolls, this method probably also has a positive effect on the paper quality in the CD direction. Also, it is quite reasonable to assume that rolls with better roundness profiles suffer less from vibration problems, have less barring problems and have improved runnability, thus reducing the maintenance costs. Further studies should be made to verify these assumptions. In addition, the "goodness" of the calculated 3D correction profile should be verified in theory. Its suitability for other types of rolls should also be studied.

\section{CONCLUSIONS}

Applications of the developed technology are not limited to the effects of high-speed paper machine rolls and the method can be applied to different kinds of rolls. The method can compensate for systematic errors arising from slideway 
errors in the lathe and roundness errors that come from the rotational error in the workpiece during the machining process.

\section{REFERENCES}

1. Kuosmanen, P., Juhanko, J. and Pullinen, J. Influence of the modernization on the dynamic behaviour of the backing roll. Paperi ja Puu (Paper and Timber), 1998, 80, 162-166.

2. Juhanko, J. Dynamic Behaviour of a Paper Machine Roll. Licentiate's thesis, Helsinki University of Technology, Laboratory of Machine Design, Espoo, 1999.

3. Dagnall, H. Let's Talk Roundness. Taylor Hobson Pneumo, Taylor Hobson Ltd., Leicester, 1996.

4. Kuosmanen, P. Predictive 3D Roll Grinding Method for Reducing Paper Quality Variations in Coating Machines. Publications in Machine Design 2/2004, Helsinki University of Technology, Espoo, 2004.

5. Pullinen, J., Juhanko, J. and Kuosmanen, P. Kunnostuksen vaikutus päällystysaseman vastatelan dynaamiseen käyttäytymiseen. Publications in Machine Design No. C 286, Helsinki University of Technology, Espoo, 1997.

6. Kuosmanen, P. and Väänänen, P. New highly advanced roll measurement technology. In Proc. 5th International Conference on New Available Techniques. Stockholm, 1996, 1056-1063.

7. Ozono, S. On a new method of roundness measurement on the three point method. In Proc. International Conference of Precision Engineering. 1974, 457-462.

8. Väänänen, P. Turning of Flexible Rotor by High Precision Circularity Profile Measurement and Active Chatter Compensation. Licentiate's thesis, Helsinki University of Technology, Laboratory of Machine Design, Espoo, 1993.

9. VTT Technical Research Centre of Finland, Calibration Certificate No. KOT36250. Ympyrämäisyyden masterkappaleet, Espoo, 1993.

10. Haikio, J. A Turning System to Minimize the Geometrical Error of a Roll. Master's thesis, Helsinki University of Technology, Laboratory of Machine Design, Espoo, 1997.

11. Kincaid, D. and Cheney, W. Numerical Analysis: Mathematics of Scientific Computing. Brooks/Cole, Pacific Grove, California, 1991.

\section{Kolmedimensiooniline treimise süsteem elastsete rootorite geomeetrilise vea vähendamiseks}

\section{Thomas Widmaier, Petri Kuosmanen, Janne Haikio ja Pekka Väänänen}

On kirjeldatud kolme anduriga lasermõõtesüsteemi, mille signaali põhjal kompenseerib täiturmehhanism rootori deformatsioone. Katsetustel tagas süsteemi kasutamine detaili diameetri telgsuunalise varieerimise vähenemise $83 \%$ ning kolmedimensioonilise geomeetrilise vea vähenemise $78 \%$. 